\title{
A importância da comunicação no sucesso de gerenciamento de projetos
}

The importance of communication in the success of project management

\section{Resumo}

A comunicação é um fator essencial em todas as fases do gerenciamento de projetos, conectando todas as partes interessadas. É através da comunicação eficiente que os objetivos dos projetos podem ser cumpridos e o sucesso dos mesmos pode ser atingido. $\bigcirc$ trabalho teve como objetivo principal avaliar a importância da comunicação no sucesso do gerenciamento de projetos. Também foram caraterizados os canais de comunicação mais utilizados, os itens que melhoram e que prejudicam a comunicação, e a satisfação com o processo de comunicação. Para tanto, o método de pesquisa através do questionário survey foi aplicado às pessoas que possuem experiência em gestão de projetos. As principais informações obtidas foram que as reuniões formais são os canais de comunicação mais utilizados pelos participantes e são também considerados os mais eficientes. Também foi levantado que papéis e responsabilidades bem definidos são os itens que melhoram a comunicação e que a centralização de informações é a maior barreira à mesma. A maior insatisfação dos participantes é com as habilidades de comunicação dos gerentes de projetos e a maior satisfação é com a comunicação entre todos os membros da equipe. A grande maioria dos participantes reconheceu a importância da comunicação, considerando-a essencial para o sucesso no gerenciamento de projetos.

Palavras-chave:

Keywords:

\section{Abstract}

Communication is a key factor in all phases of project management, connecting all stakeholders. It is through efficient communication that the objectives of projects can be full filled and their success can be achieved. The aim of this work was to evaluate the importance of communication in the success of project management. The most commonly used communication channels, the items that improve and impair communication, and satisfaction with the communication process were also characterized. To do so, the survey method was applied to people who have experience in project management. The main information obtained was that formal meetings are the communication channels most used by participants and are also considered the most efficient. It was also pointed out that well-defined roles and responsibilities are the items that improve communication more and that centralization of information is the biggest barrier to it. The greatest dissatisfaction among participants is with the communication skills of project managers and the greatest satisfaction is with communication among all team members. The vast majority of participants recognized the importance of communication as essential for success in project management. 


\section{INTRODUÇÃO}

Durante o desenvolvimento de projetos, os gerentes estão em constante comunicação com os membros da equipe, pessoas externas, stakeholders, entre outros. A habilidade de se comunicar com eficácia é um elemento que conecta as partes interessadas e ultrapassa diferenças de opiniões, perspectivas, culturas, nível de conhecimento, entre outros (PMI, 2014). Assim, a comunicação eficiente é um dos fatores fundamentais para o sucesso no gerenciamento de projetos (BUBSHAIT; SIDDIQUI; AL-BUALI, 2015; RAMSING, 2009).

Para atingir os objetivos e ter sucesso nos projetos, é necessário estabelecer canais robustos de comunicação para que todos estejam no mesmo patamar de conhecimento e entendimento, propiciando oportunidades de formação da equipe e um ambiente de confiança (PMI, 2014). Deste modo, a entrega de informações importantes através das melhores vias de comunicação no tempo apropriado garantirá o entendimento do projeto (CHEN; WEI; HUANG, 2013) e facilitará a tomada de decisões de forma colaborativa (PMI, 2014), melhorando o desempenho do mesmo.

Diversos fatores influenciam na comunicação entre equipes. Diferenças culturais podem trazer diferentes perspectivas, habilidades e atributos pessoais. Tais diferenças devem ser compreendidas pelo gestor de projetos, criando um sistema de comunicação eficiente entre clientes, equipe e gerentes (OCHIENG; PRICE, 2010). O clima de confiança e respeito desenvolve a comunicação e o comportamento cooperativo, tornando a equipe mais predisposta a compartilhar informações (CHEUNG; YIU; LAM, 2013). Disponibilidade de informações e gestão de conflitos técnicos, papéis e responsabilidades bem definidos, visão sistemática de todo o processo, conhecimento sobre as informações necessárias a terceiros, também são fatores fundamentais que influenciam diretamente na comunicação (MAIER et al., 2008). Discursos diretos e indiretos entre os membros da equipe, ou seja, ou utilizando metáforas, dicas, ironias ou dizendo exatamente o que se deseja (YIN; KUO, 2013) e até a comunicação verbal e não verbal (GILLARD; JOHANSEN, 2004) também atuam significativamente nos processos de comunicação.

É com base no reconhecido papel que a comunicação exerce no gerenciamento de projetos que este trabalho apresenta os principais fatores da comunicação que influenciam no sucesso de projetos. Também são analisados os benefícios e a importância que a comunicação, eficiente e bem direcionada, traz para os mesmos. Os canais de comunicação mais utilizados durante as fases de iniciação, desenvolvimento e encerramento são elencados, bem como a percepção da eficiência dos mesmos. $\mathrm{O}$ método de pesquisa utilizado no trabalho foi o questionário survey, aplicado às pessoas com experiência em gestão de projetos.

Na próxima seção, 2-Revisão de Literatura, são abordados os conceitos e trabalhos publicados na área de comunicação e sucesso de projetos. A seção 3-Metodologia contempla o desenvolvimento e 
descrição do survey que será aplicado no trabalho para levantamento e coleta de dados. Na seção 4, são compilados e analisados os resultados do survey. A seção 5-Conclusão apresenta as conclusões deste trabalho, destacando pontos importantes da comunicação a serem considerados para atingir o sucesso de projeto.

\section{FUNDAMENTAÇÃO TEÓRICA}

A importância da comunicação é um elemento conhecido no universo de gerenciamento de projetos. Equipes de projetos necessitam de informações para cumprir o escopo dos projetos; as partes interessadas precisam estar atualizadas sobre o status e desenvolvimento; as agências financiadoras necessitam das comprovações de pagamentos e de utilização dos recursos disponibilizados (DOW; TAYLOR, 2008). Bubshait, Siddiqui e Al-Buali (2015) destacam um elemento importante: o gerente de projetos. A comunicação e coordenação são fatores essenciais para a gestão de projetos, pois aumentam o desempenho do mesmo. Gerentes de projeto devem falar e ouvir a equipe de projeto, agregando as opiniões da equipe às suas próprias (CLEMENTS; GIDO, 2014). Para Kliem (2008) os gerentes de projeto devem adaptar a comunicação para preencher os requisitos únicos de cada projeto e atender todas as partes interessadas.

Neste contexto, a escolha dos canais de comunicação adequados influencia na transmissão da informação de forma eficiente. Tais canais podem divididos em formais, através de processos que seguem regras e padrões determinados, ou informais, realizados através de conversas interpessoais e telefonemas, por exemplo. A comunicação informal também pode ser verbal, quando há o emprego de palavras, e não-verbal, quando há interpretação de sinais corporais. Além disso, os canais também podem ser divididos em escritos e digitais (CHAVES et al., 2014).

Os canais de comunicação devem ser utilizados de acordo com o tipo de receptor da informação. Ao compreender o tipo de receptor, pode-se utilizar uma comunicação mais direta e eficaz, capaz de atender as expectativas do mesmo (FRANÇA, 2003). Ou seja, para cada tipo de receptor da mensagem existe um canal mais adequado para a comunicação, conforme Quadro 1.

De acordo com Kliem (2008), gerentes de projetos utilizam pelo menos 80 a $90 \%$ de seu tempo comunicando-se com sua equipe ou com as partes interessadas. Neste sentido, Chaves et al. (2014) apresenta a pesquisa PMSurvey realizada pelo Project Management Institute (PMI) em 2012, que revela que em 692 organizações do Brasil a comunicação é principal habilidade necessária e valorizada no gerenciamento de projetos. Segundo esta pesquisa, a comunicação está à frente de habilidades como liderança, negociação, conhecimento técnico, gestão de conflitos, entre outros. 
Quadro 1 - Planejamento da comunicação e do uso de seus instrumentos.

\begin{tabular}{|c|c|c|}
\hline $\begin{array}{c}\text { Determinação } \\
\text { dos públicos }\end{array}$ & $\begin{array}{c}\text { Como a comunicação deve ser } \\
\text { planejada de acordocom públicos } \\
\text { específicos }\end{array}$ & $\begin{array}{c}\text { Instrumentos preferenciais que podem ser } \\
\text { utilizados (mídia selecionada) }\end{array}$ \\
\hline Empregados & $\begin{array}{l}\text { Direta, permanente, informativa, } \\
\text { motivacional, interativa e persuasiva }\end{array}$ & $\begin{array}{l}\text { Encontros de comunicação, reuniões, eventos, } \\
\text { publicações, intranet }\end{array}$ \\
\hline Acionistas & $\begin{array}{l}\text { Direta, informativa, transparente, com } \\
\text { regularidade, do tipo prestação de } \\
\text { contas semestrais e anuais }\end{array}$ & $\begin{array}{l}\text { Reuniões, boletins, informativos, relatórios } \\
\text { semestrais, anuais, intemet, intranet }\end{array}$ \\
\hline Fomecedores & $\begin{array}{l}\text { Direta, informativa, com regularidade, } \\
\text { tecnológica, precisa, transparente, } \\
\text { motivacional, manifestadora de } \\
\text { interesses, de manutenção de parcerias, } \\
\text { de satisfação pelo serviço recebido, } \\
\text { cobrança de prazos e de cumprimento } \\
\text { cronograma }\end{array}$ & $\begin{array}{l}\text { Informativos, visitas, encontros, debates, } \\
\text { jomais, pesquisas, manuais técnicos, folhas de } \\
\text { especificações de produtos, intranet, intemet }\end{array}$ \\
\hline Clientes & $\begin{array}{l}\text { Direta, persuasiva, motivadora, } \\
\text { permanente e sazonal (campanhas), } \\
\text { promocional, criativa, chamando } \\
\text { atenção, despertando interesse, desejo } \\
\text { de compra, e de manutenção da } \\
\text { fidelidade à marca }\end{array}$ & $\begin{array}{l}\text { Publicações, informativos, } \\
\text { campanhas, outdoors, rádio, televisãa, } \\
\text { merchandising, faixas, prêmios, coleções, } \\
\text { sorteios, ofertas, eventos }\end{array}$ \\
\hline Comunidade & $\begin{array}{l}\text { Direta, com regularidade, informativa, } \\
\text { motivacional, transmissora de valores e } \\
\text { politicas empresariais, para conquistar } \\
\text { apoio e interesse pela empresa, pela sua } \\
\text { defesa }\end{array}$ & $\begin{array}{l}\text { Encontros, projetos sociais, patrocínios, } \\
\text { parcerias, publicações, eventos }\end{array}$ \\
\hline Govemo & $\begin{array}{l}\text { Direta, de regularidade bem planejada, } \\
\text { informativa, tecnológica, transparente, } \\
\text { persuasiva e ética }\end{array}$ & $\begin{array}{l}\text { Contatos diretos, visitas, encontros, aç̃̃es de } \\
\text { lobby, audiências, relatónios, projetos }\end{array}$ \\
\hline
\end{tabular}

Fonte: França (2003).

Em ambientes organizacionais pode-se facilmente detectar barreiras à comunicação, como centralização das informações, canais inadequados, falta de clareza nas mensagens e até mesmo a conhecida "fofoca", dificultando o desenvolvimento de projetos (CARVALHO; RABECHINI JR., 2015). De acordo com Kerzner (2009), a comunicação pobre é a maior inimiga do desenvolvimento eficaz de uma equipe e pode ocorrer em quatro níveis: entre os membros da equipe, entre o gerente de projetos e o líder do projeto, entre líder do projeto e o gerente, e entre os líderes de projeto e os clientes.

A ineficiência das comunicações ocorre quando membros da equipe não mantêm as partes interessadas informadas sobre o desenvolvimento do projeto. A falta de informações pode ocorrer por vários motivos, entre eles: baixa motivação, falta de ética ou descuido (KERZNER, 2009). Alguns autores destacam que a falta de comunicação entre os membros da equipe leva a problemas de construção do espírito de equipe e de confiança. Apesar da confiança ser difícil de ser quantificada, pois trata-se de algo intangível e frágil, ela é um fator essencial para o sucesso do projeto (DIALLO; THUILLIER, 2005; OCHIENG; PRICE, 2010). Destaca-se que quando há falta de confiança, os membros da equipe não estão predispostos a compartilhar informações e portanto o desempenho do projeto é influenciado negativamente (CHEUNG; YIU; LAM, 2013).

No contexto da problemática da comunicação e suas consequências, ressalta-se que, particular- 
mente em novos projetos, a comunicação pode influenciar não somente os envolvidos nas mudanças, mas a organização como um todo (CLARKE, 1999). Gerentes de projeto devem reconhecer a comunicação como uma das competências importantes no gerenciamento de projetos. Porém, implementar esforços de adaptação e de melhoria da comunicação pode reduzir o ritmo de trabalho já alcançado e gerar retrabalho. É por este motivo que, muitas vezes, os gerentes não querem aplicar ou desenvolver melhorias na comunicação (KLIEM, 2008).

A pesquisa do PMSurvey realizada pelo Project Management Institute (PMI) em 2012 comprova que o problema mais frequente em projetos é a comunicação (CHAVES et al., 2014). Em 2016, esta pesquisa ainda aponta a comunicação com principal habilidade no gerenciamento de projetos, e também a comunicação como o principal problema em projetos.

Ao utilizar eficientemente a comunicação, incertezas podem ser melhor gerenciadas, evitando retrabalhos e identificando problemas mais rapidamente. Além disso, a motivação da equipe é favorecida e garante-se o envolvimento de todas as partes interessadas (CLARKE, 1999). A comunicação eficiente deve considerar os interesses e níveis de comprometimento das partes interessadas, adaptando as informações conforme necessário. Também deve considerar possíveis diferenças culturais e técnicas existentes, visto que equipes de projeto geralmente são multidisciplinares (CERVONE, 2014).

Atingir o nível desejado de comunicação em projetos é um processo desafiador, cuja responsabilidade recai, muitas vezes, sobre o gerente de projetos. O gerente é o agente regulador do processo de comunicação, pois é através dele que as informações fluem para todas as partes interessadas do projeto (KLIEM, 2008). É papel do gerente conversar com todos e coletar ideias na tentativa de descobrir opiniões, contribuições, receios e preocupações. Para que isso ocorra, é necessário trabalhar em conjunto na escuta eficaz: ser ouvido, ouvir, entender e ser entendido (CLEMENTS; GIDO, 2014).

Além do papel do gerente de projetos, é importante considerar também o papel dos membros da equipe na comunicação interna das organizações. Segundo Ruck e Welch (2012) "a comunicação interna efetiva é um pré-requisito para o sucesso das organizações". Ao incorporar as vozes dos membros da equipe, há aumento da produtividade e da motivação dos mesmos, influenciando as comunicações internas das organizações e a gestão de comunicação da equipe e consequentemente o sucesso das organizações.

\section{PROCEDIMENTOS METODOLÓGICOS}

O objetivo deste trabalho é investigar a importância da comunicação para atingir o sucesso de projetos. Para isto foi analisado o papel que a comunicação desempenha em projetos de sucesso, quais fatores/canais podem interferir positivamente ou negativamente na comunicação e quais canais são mais utilizados e eficientes.

Os métodos de pesquisa utilizados foram a pesquisa bibliográfica e a coleta de dados através da 
aplicação de um questionário survey.

A pesquisa bibliográfica foi realizada através de artigos publicados em periódicos nacionais e internacionais e livros. Foram levantados, principalmente, artigos referenciando o estado da arte do tema comunicação em projetos e suas implicações para o sucesso dos mesmos. O questionário survey foi aplicado como método de pesquisa descritiva. Neste tipo de pesquisa são observados e levantados acontecimentos do passado ou do presente momento sem interferência do pesquisador (KOTHARI, 2004). A pesquisa através do survey envolve a coleta de informações entre as pessoas, podendo ser de natureza pessoal ou social. Assim, através dos dados amostrais, pode-se extrapolar a informação para a população (CHOW; CAO, 2008).

Além de descritivo, o questionário survey também foi do tipo qualitativo, pois diz respeito à avaliação de opiniões que não podem ser quantificados (KOTHARI, 2004) e são, portanto, de análise indutiva (GODOY, 1995).

O questionário foi desenvolvido através de uma plataforma de perguntas online: o Google Forms. O mesmo foi enviado e respondido por pessoas envolvidas no universo de gerenciamento de projetos, focando aquelas com experiência profissional na área e que atuam tanto como gerentes ou como parte da equipe de projetos. Após a coleta de dados das respostas do questionário, os mesmos foram compilados, tabulados e analisados estatisticamente de forma a atingir ou refutar os objetivos do trabalho.

\section{RESULTADOS E DISCUSSÕES}

\subsection{Percepção dos gerentes de projetos quanto ao perfil de competências essenciais de um profissional de projetos}

O questionário foi respondido por um total de 49 participantes. No quesito escolaridade, 32,7\% dos participantes possuem ensino superior completo, $65,3 \%$ possuem pós-graduação ou MBA e $2 \%$ mestrado ou doutorado. Os participantes ocupam os mais variados cargos, sendo que analistas/engenheiros representam $56 \%$ e coordenadores, gerentes e diretores representam $38 \%$ do total. Técnicos, tecnólogos e doutorandos representam $2 \%$. Em relação ao tempo de experiência em gestão de projetos, $65,3 \%$ dos participantes possuem até 5 anos de experiência, 20,4\% entre 6 a 10 anos, 10,2\% entre 11 a 15 e 4,1\% acima de 21 anos. A maioria dos entrevistados, cerca de 67,3\%, trabalha em empresas nacionais, e 32,7\% em empresas multinacionais. A área de atuação das empresas está majoritariamente dividida em 3 segmentos: construção civil, com 31,2\%, água e esgoto com 27,1\% e indústria, com 16,7\%. Essas três áreas representam 75\% do total. Os demais segmentos são das áreas de transportes, tecnologia da informação, comércio, telefonia, entre outros.

$\mathrm{Na}$ pesquisa, foram levantadas informações tanto sobre os processos de comunicação dentro das empresas, bem como as percepções dos participantes sobre os mesmos. Também foram mapeados os 
canais de comunicação utilizados para iniciar, desenvolver e finalizar um projeto, bem como as opiniões dos participantes sobre a eficiência dos mesmos.

O canal de comunicação mais utilizado para iniciar um projeto na empresa dos participantes foi a reunião formal, com 49\%. O segundo mais utilizado foi o e-mail, com 24,5\%. Em terceiro lugar, foi a comunicação face a face com 20,4\%. Demais canais, tais como telefone, relatórios e áudio conferência aparecem com $2 \%$.

Os participantes foram questionados sobre os canais mais utilizados nas empresas para informar o status e o desenvolvimento dos projetos. As reuniões formais são os canais mais utilizados, com $36,7 \%$. A seguir, são utilizados e-mails com 32,7\%, relatórios com 20,4\%, comunicação face a face, com $6,1 \%$ e vídeos e áudio conferências, ambas com $2 \%$.

Em relação à pergunta, "Em sua opinião, o canal mais utilizado para informar o status e o desenvolvimento do projeto na sua empresa é o mais eficiente?”, a maioria dos participantes $(57,1 \%)$ afirmou que utiliza os canais mais eficientes. Porém, 42,9\% responderam que não utilizam os canais mais eficientes. Ainda nesta pergunta, os participantes que não utilizam os canais mais eficientes selecionaram aqueles que, em sua opinião, são mais eficientes. Os resultados obtidos elencaram as reuniões formais em primeiro lugar, com 16,8\%. Em segundo lugar aparecem os e-mails, com 9,3\% e em terceiro lugar os relatórios, com 7,5\%. A Figura 1 ilustra todos os resultados obtidos, onde o gráfico à esquerda representa a resposta à pergunta sobre a utilização dos canais mais eficientes para informar o status e o gráfico à direita representa os percentuais de participantes que, ao não utilizarem os canais mais eficientes, elencaram aqueles que consideram mais eficientes, para informar o desenvolvimentos dos projetos.

Considerando os resultados apresentados acima, pode-se concluir que as reuniões formais são os canais mais utilizados para acompanhamento dos projetos e que mesmo a grande parcela de participantes que não as utilizam, consideram-na mais eficiente em relação aos outros tipos de canais.

Os participantes foram questionados também sobre o canal de comunicação mais utilizado nas empresas para distribuir tarefas às equipes de projeto. As reuniões formais são os canais mais utilizados, com 36,7\%. A seguir, são utilizados e-mails com 32,7\%, relatórios com 20,4\%, comunicação face a face, com $6,1 \%$ e vídeos e áudio conferências, ambas com $2 \%$.

Em relação à pergunta, "Em sua opinião, o canal mais utilizado para informar o status e o desenvolvimento do projeto na sua empresa é o mais eficiente?”, a maioria dos participantes $(57,1 \%)$ afirmou que utiliza os canais mais eficientes. Porém, 42,9\% responderam que não utilizam os canais mais eficientes. Ainda nesta pergunta, os participantes que não utilizam os canais mais eficientes selecionaram aqueles que, em sua opinião, são mais eficientes. Os resultados obtidos elencaram as reuniões formais em primeiro lugar, com 16,8\%. Em segundo lugar aparecem os e-mails, com 9,3\% e em terceiro lugar os relatórios, com 7,5\%. A Figura 1 ilustra todos os resultados obtidos, onde o gráfico à esquerda representa a resposta à pergunta sobre a utilização dos canais mais eficientes para 
informar o status e o gráfico à direita representa os percentuais de participantes que, ao não utilizarem os canais mais eficientes, elencaram aqueles que consideram mais eficientes, para informar o desenvolvimentos dos projetos.

Considerando os resultados apresentados acima, pode-se concluir que as reuniões formais são os canais mais utilizados para acompanhamento dos projetos e que mesmo a grande parcela de participantes que não as utilizam, consideram-na mais eficiente em relação aos outros tipos de canais.

Os participantes foram questionados também sobre o canal de comunicação mais utilizado nas empresas para distribuir tarefas às equipes de projeto. As reuniões formais aparecem com 32,7\% das respostas. Adicionalmente, há um empate entre e-mails e comunicação face a face, com 30,6\%. Geração de relatórios e vídeo conferência aparecem com $4,1 \%$ e 2,0\%, respectivamente.

Figura 1 - Canais de comunicação mais eficientes

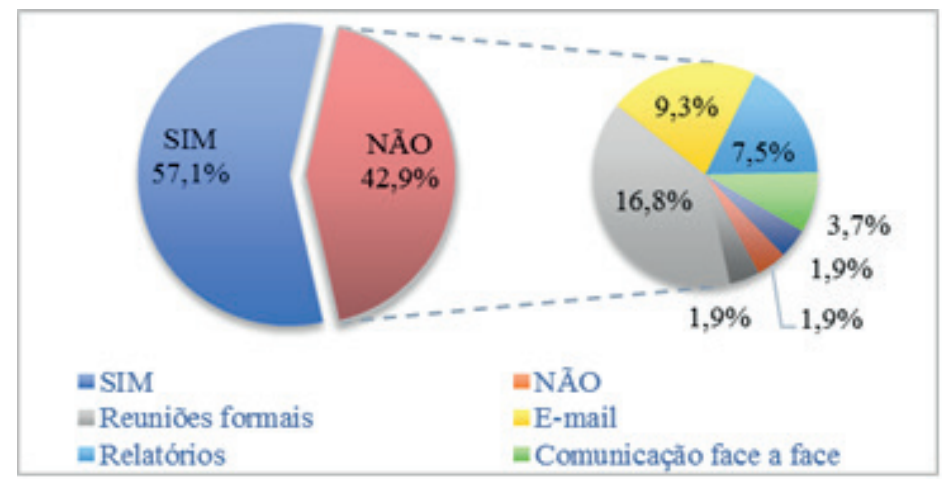

Fonte: Autores (2019).

Segundo as respostas, o canal mais utilizado com a finalidade de distribuir tarefas é também o mais eficiente para a grande maioria dos participantes, com $71 \%$. Porém, para os outros $29 \%$, os canais mais eficientes são as reuniões formais, seguidos por e-mails e relatórios. A Figura 2 apresenta os percentuais de utilização dos canais mais eficientes para distribuir tarefas de acordo com a visão de cada participante.

Figura 2 - Canais de comunicação mais eficientes.

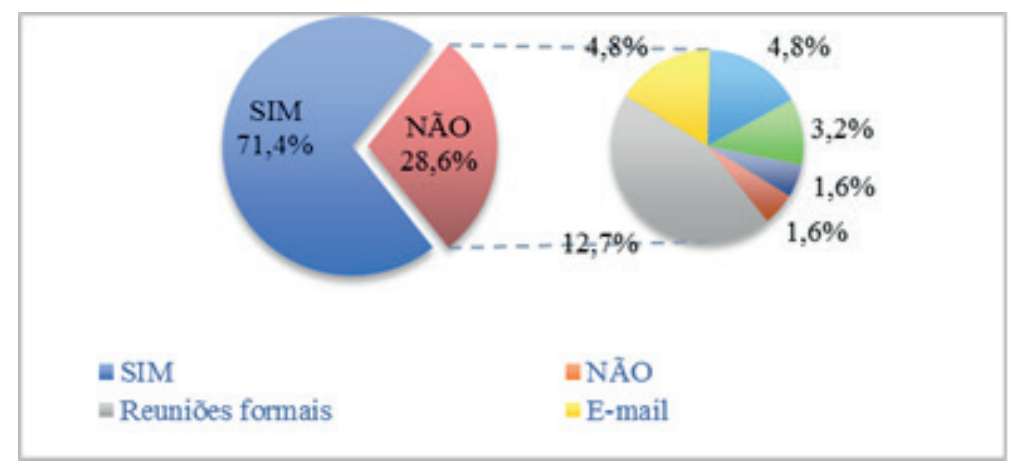

Fonte: Autores (2019). 
A próxima pergunta focou no encerramento do projeto. Para tanto, o participante foi questionado sobre o canal de comunicação mais utilizado para encerrar um projeto. As reuniões formais aparecem em primeiro lugar, sendo utilizadas por $42,9 \%$ dos participantes. E-mails e relatórios aparecem empatados em segundo lugar, com 20,4\% das respostas. Além disso, 14,3\% dos entrevistados utilizam a comunicação face a face, e $2 \%$ vídeo conferências.

O planejamento das comunicações traz como principal benefício a identificação do método de comunicação mais eficaz e eficiente entre todas as partes interessadas (PMI, 2014). Nesse contexto, foi questionada a percepção dos participantes sobre a melhoria da eficiência da comunicação ao aplicar o plano de comunicação. Para 51\% dos participantes, o plano melhora muito a eficiência da comunicação. Já para 24,5\%, o plano melhora apenas satisfatoriamente e $24,5 \%$ não possuem plano de comunicação. Tais resultados corroboram a literatura e evidenciam a importância do plano de comunicação nos projetos.

Em seguida, foram propostos para os participantes 7 fatores que podem melhorar a comunicação nos projetos e, dentre esses, cada respondente escolheu os 3 fatores mais relevantes. Os três fatores mais recorrentes foram: papéis e responsabilidades da equipe bem definidos $(22,4 \%)$, seguidos de comprometimento da equipe $(17,7 \%)$ e maior frequência de troca de informações $(16,3 \%)$. Tais resultados indicam que a comunicação flui melhor quando se mantém uma equipe com objetivos bem estruturados e também comprometida com os resultados, conforme encontrado em Clarke (1999). A Figura 3 mostra os resultados de todos os fatores.

Figura 3 - Fatores que melhoram a comunicação.



Fonte: Autores (2019).

Os participantes também elencaram 3 barreiras que mais prejudicam as comunicações. As três barreiras mais votadas foram: centralização de informações, falta de habilidades de comunicação do gerente de projetos e falta de objetivos e metas claras do projeto. Dow e Taylor (2008) e Kerzner (2009) salientam a comunicação entre todas as partes interessadas como fator essencial para desenvolvimento dos projetos. Nesse contexto, a centralização das informações como a barreira à comunicação mais votada pelos participantes confirma os dois autores. A falta de habilidades de comunicação 
do gerente como segundo item mais votado também merece destaque, pois, conforme Kliem (2008), o papel do gerente nos processos de comunicação é crucial para garantir o bom desenvolvimento dos projetos. A Figura 4 apresenta as barreiras elencadas.

A existência de barreiras de comunicação causa diversas consequências negativas nos projetos. Para os participantes, o retrabalho é o item mais frequente, destacando-se com mais de $30 \%$ das respostas. Os demais itens apresentaram resultados similares, que variaram entre 9 a 13\%. As respostas são apresentadas na Figura 5. Em relação à satisfação com a comunicação, foram levantados os itens que mais e menos satisfazem os participantes. O item que mais satisfaz é a comunicação entre todos os membros da equipe. Já o item que menos satisfaz são as habilidades de comunicação do gerente de projetos. A Figura 6 ilustra os itens que mais e menos satisfazem os participantes.

Figura 4 - Barreiras à comunicação

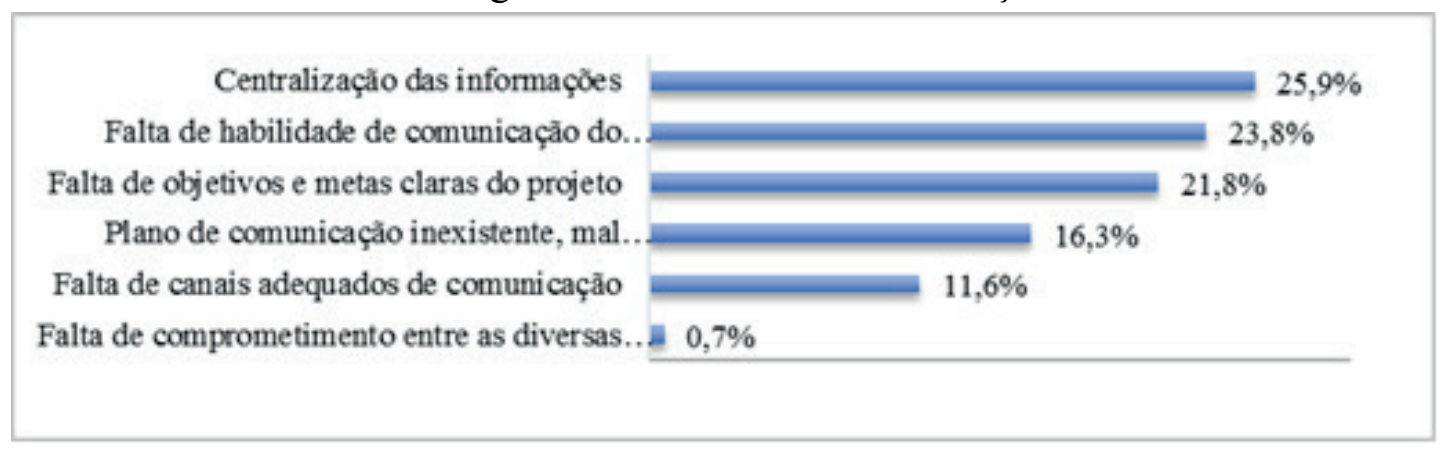

Fonte: Autores (2019).

Figura 5 - Consequências negativas das barreiras à comunicação.

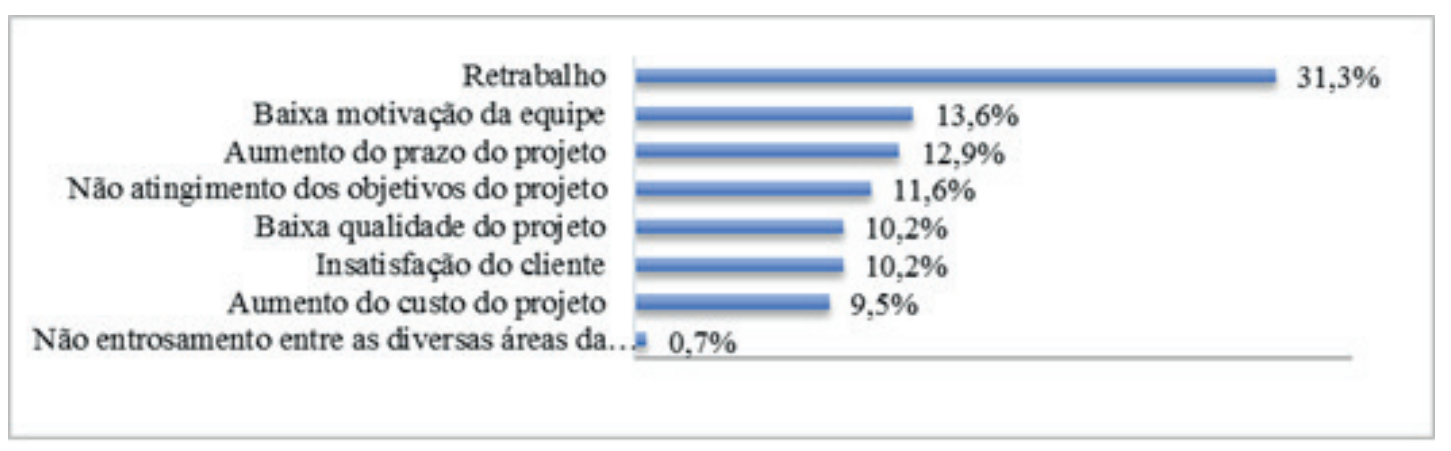

Fonte: Autores (2019).

Os participantes também foram questionados sobre suas percepções em relação à comunicação e o sucesso de projetos. Para 53\% dos participantes, o plano de comunicação é essencial para o sucesso dos projetos, já 35\% deles classificaram o plano de comunicação como muito importante, 12\% classificaram como pouco ou medianamente importante e ninguém classificou como não importante.

O papel do gerente no processo de comunicação para o sucesso de projetos também foi analisado. Para 53\% dos participantes, o gerente de projetos é essencial nesse quesito. O gerente é considera- 
do importante para 39\% e, novamente, ninguém classificou o papel do mesmo como pouco ou não importante. Os resultados destacam o papel fundamental do gerente no processo de comunicação, conforme encontrado em Kliem (2008).

Figura 6 - Itens que mais e menos satisfazem os participantes na comunicação.
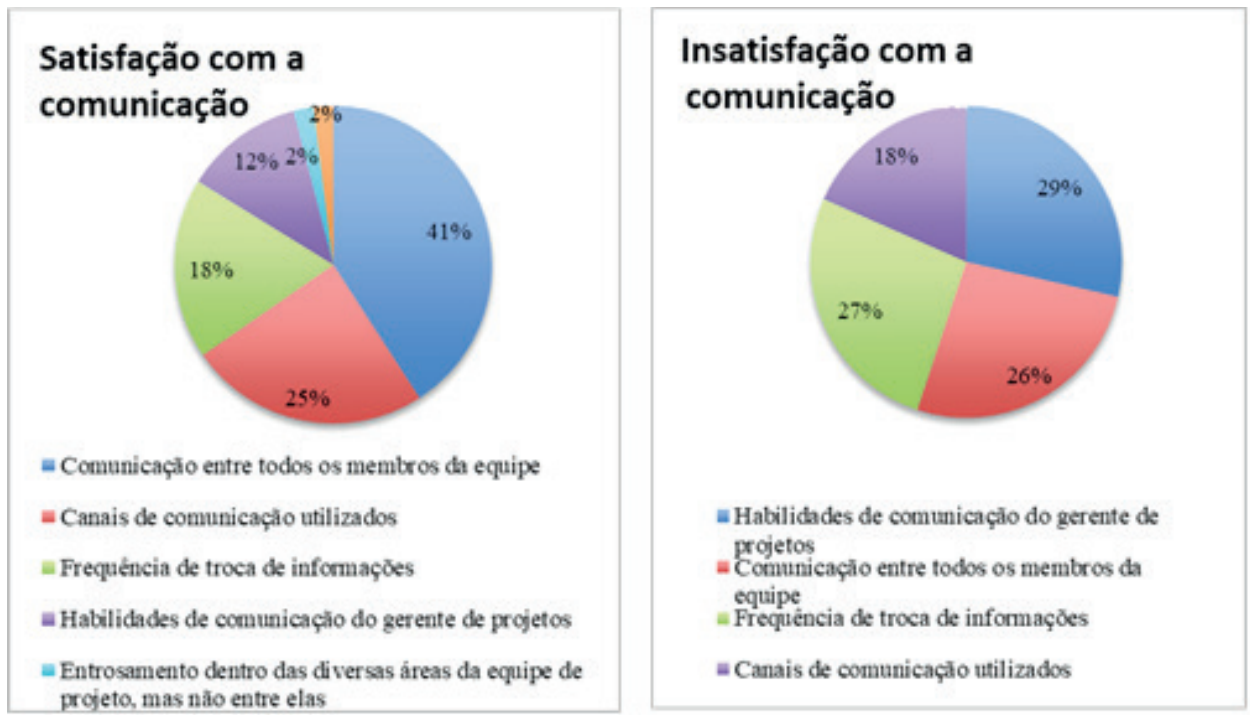

Fonte: Autores (2019).

Também foi analisada a relação direta da comunicação com o sucesso dos projetos. Segundo $80 \%$ dos participantes, a comunicação é essencial para obter sucesso nos projetos. Para o restante dos entrevistados, a comunicação é muito importante. Tais resultados corroboram com o que é encontrado na fundamentação teórica, conforme Clarke (1999) e Hyvari (2006).

\section{CONCLUSÕES}

O objetivo deste trabalho foi atingido, pois foi possível demonstrar a importância da comunicação para alcançar o sucesso de projetos através da análise das percepções dos participantes.

Através dos resultados obtidos do questionário, foram mapeados os canais de comunicação utilizados no início, desenvolvimento e encerramento do projeto. As reuniões formais aparecem como os meios de comunicação mais utilizados e também os mais eficientes para acompanhar o desenvolvimento e distribuição das tarefas às equipes de projetos.

Foram levantados fatores que melhoram e que prejudicam a comunicação. Papéis e responsabilidades bem definidos, comprometimento, maior frequência de troca de informações e objetivos claros do projeto aparecem como itens que melhoram a comunicação dos projetos. A existência de um plano de comunicação também foi elencada como um fator que melhora a comunicação. Na contramão, aparecem como principais barreiras à comunicação a centralização de informações, a falta de habili- 
dades de comunicação do gerente de projetos e a falta de objetivos claros. Segundo os participantes, tais barreiras geram como principal consequência o retrabalho.

A importância do gerente de projetos na comunicação é reconhecida no âmbito do gerenciamento de projetos e a mesma foi comprovada através da pesquisa aplicada. Assim, a insatisfação dos participantes com as habilidades de comunicação do gerente de projetos é um item que merece destaque e, talvez, pesquisas posteriores que identifiquem possíveis pontos de melhoria.

Através desse trabalho, foi possível constatar que a gestão da comunicação pode influenciar o sucesso de gerenciamento de projetos. A comunicação foi um fator considerado essencial para atingir o sucesso pela maioria dos participantes. Inclusive quando comparada a outros fatores que influenciam no sucesso elencados por Pinto e Slevin (1988), a comunicação obteve destaque nas respostas, considerada como o segundo fator essencial, atrás somente de aceitação do cliente.

Por fim, como recomendação para trabalhos futuros, sugere-se o aumento do número de participantes, visando principalmente pessoas com maior tempo de experiência em gestão de projetos. Outro ponto levantado é a utilização do questionário como método de pesquisa. Apesar da maioria das perguntas ser aberta, possibilitando aos participantes redigirem as próprias respostas, verificou-se que quase não houve contribuições deste tipo. Os participantes limitaram-se a escolher suas respostas entre os itens pré-definidos. É por este motivo que se sugere a aplicação de outros métodos de pesquisa, como por exemplo entrevistas, para que a gama de respostas aumente e possa enriquecer mais o trabalho.

\section{Referências}

BUBSHAIT, A. A.; SIDDIQUI, M. K.; AL-BUALI, A. M. A. Role of Communication and Coordination in Project Success: Case Study. Journal of Performance of Constructed Facilities, v. 29, n. 4, p. 1-7, 2015.

CARVALHO, M. M. DE; RABECHINI JR, R. Fundamentos da gestão de projetos. 4. ed. São Paulo: Atlas, 2015.

CERVONE, H. F. Effective communication for project success. OCLC Systems \& Services, v. 30, n. 2, p. 74-77, 2014.

CHAVES, L. E; NETO, F. H. S; PECH, G; CARNEIRO, M. F. S. Gerenciamento da Comunicação em Projetos. 3. ed. Rio de Janeiro: Atlas, 2014.

CHEN, Q.-L.; WEI, C-S; HUANG, M-Y. A model for project communication medium evaluation and selection. Concurrent Engineering-Research and Applications, v. 21, n. 4, p. 237-251, 2013. CHEUNG, S. O.; YIU, T. W.; LAM, M. C. Interweaving Trust and Communication with Project Performance. Journal of Construction Engineering and Management, v. 139, n. 8, p. 941-950, 2013. CHOW, T.; CAO, D. A survey study of critical success factors in agile software projects. The Jour- 
nal of Systems and Software, v. 81, p. 961-971, 2008.

CLARKE, A. A practical use of key success factors to improve the efectiveness of project management. International Journal of Project Management, v. 17, n. 3, p. 139-145, 1999.

CLEMENTS, J. P.; GIDO, J. Gestão de projetos. 5. ed. São Paulo: Cengage Learning, 2014.

DIALLO, A.; THUILLIER, D. The success of international development projects, trust and communication: An African perspective. International Journal of Project Management, v. 23, n. 3, p. 237-252, 2005.

DOW, W.; TAYLOR, B. Project Management Communications Bible. Indianapolis: Wiley Publishing, 2008.

FRANÇA, F. Conceituação lógica de públicos em Relações Públicas. Revista de Estudos de Jornalismo e Relações Públicas, São Bernardo do Campo: UMESP, Ano I, n.1, jun. 2003.

GILLARD, S.; JOHANSEN, J. Project Management Communication: a Systems Approach. Journal of Information Science, v. 30, n. 1, p. 23-29, 2004.

GODOY, A. S. Introdução à pesquisa qualitativa e suas possibilidades. Revista de Administração de Empresas, v. 35, n. 2, p. 57-63, 1995.

HYVARI, I. Success of Projects in Different Organizational Conditions. Project Management Journal, v. 37, n. 4, p. 31-42, 2006.

KERZNER, H. Project Management - A Systems Approach to Planning, Scheduling and Controlling. 10. ed. New Jersey: John Wiley \& Sons, 2009.

KLIEM, R. L. Effective communications for project management. 1. ed. New York: Auerbach Publications, 2008.

KOTHARI, C. R. Research Methodology: Methods and Techniques. 3. ed. New Delhi: New Age International, 2004.

MAIER, A. M.; KREIMEYER, M.; HAPPERLE, C.; ECKERT, C. M.; LINDEMANN, U.; CLARKSON, P. J. Exploration of correlations between factors influencing communication in complex product development. Concurrent Engineering: Research and Applications, v. 16, n. 1, p. 37-59, 2008.

OCHIENG, E. G.; PRICE, A. D. F. Managing cross-cultural communication in multicultural construction project teams: The case of Kenya and UK. International Journal of Project Management, v. 28, n. 5, p. 449-460, 2010.

PINTO, J. K.; SLEVIN, D. P. Critical success factors across the project life cycle. Project Management Journal, v. 19, n. 3, p. 67-75, 1988.

PMI. Um guia do conhecimento em gerenciamento de projetos (guia PMBOK). 5. ed. Pennsylvania: Project Management Institute, 2014. v. 1

RAMSING, L. Project communication in a strategic internal perspective. Corporate Communications: An International Journal, v. 14, n. 3, p. 345-357, 2009.

RUCK, K.; WELCH, M. Valuing internal communication; management and employee perspectives. 
Public Relations Review, v. 38, n. 2, p. 294-302, 2012.

YIN, C. P.; KUO, F. Y. A study of how information system professionals comprehend indirect and direct speech acts in project communication. IEEE Transactions on Professional Communication, v. 56, n. 3, p. 226-241, 2013. 